\title{
Diagnosis and Surgical Extraction of Large Gastric Trichobezoars: A Single Center Study of Two Cases
}

\author{
Tulika Saggar ${ }^{1}$, Varun Saggar ${ }^{2, *}$ \\ ${ }^{1}$ Dayanand Medical College and Hospital, Ludhiana, Punjab, India \\ ${ }^{2}$ Department of Surgery, Lord Mahavir Civil Hospital, Ludhiana, Punjab, India \\ Email address: \\ saggartulika@gmail.com (T. Saggar), varun.saggar7@gmail.com (V. Saggar) \\ ${ }^{*}$ Corresponding author
}

To cite this article:

Tulika Saggar, Varun Saggar. Diagnosis and Surgical Extraction of Large Gastric Trichobezoars: A Single Center Study of Two Cases. International Journal of Gastroenterology. Vol. 4, No. 2, 2020, pp. 45-49. doi: 10.11648/j.ijg.20200402.14

Received: July 5, 2020; Accepted: July 17, 2020; Published: August 4, 2020

\begin{abstract}
Trichobezoars are compact mass of hair occupying the gastric cavity that if left untreated can cause developmental delay, malnutrition, obstruction or perforation. The treatment options include extraction by conventional laparotomy, laparoscopy, gastrotomy or endoscopy. Since they are almost always associated with trichotillomania and trichophagia or other psychiatric disorders, psychiatric consultation is necessary to prevent relapses. We reviewed the medical charts of two patients with trichobezoar who were treated at Lord Mahavir, Civil Hospital, Ludhiana. Both the cases, aged 14 and 19 years were females and presented at the hospital with a history of epigastric discomfort, pain and vomiting. Both the girls were lean, underweight and pale skinned. First patient had trichotillomania and trichophagia for 1 year prior to presentation. The parents were unaware of patient's trichophagia but the girl revealed that she ate hair during the night. The second patient had no history of trichophagia and the bilateral loss of scalp hair indicated nocturnal involuntary eating of hair during sleep. The large palpable mass in both the cases was non-tender, hard, smooth and mobile on examination. The abdominal imaging with CT revealed the mass occupying most of the gastric cavity, and turned out to be trichobezoars. The masses were successfully extracted by laparotomy and gastrotomy. A trichobezoar represents a serious surgical condition. It is important to consider such diagnosis in face of suggestive symptoms, even if signs of trichotillomania are not present. Gastrotomy was found to be very successful for the surgical removal of trichobezoars. The behavioral assessment and psychiatric counselling also plays a useful role in patient management and prevention of recurrence.
\end{abstract}

Keywords: Trichobezoar, Trichotillomania, Gastrotomy, Case Report

\section{Introduction}

Trichobezoar is a rare medico-surgical condition, comprising of compact mass of hair occupying the gastric cavity to a varying extent, mostly affecting young women [14]. In most cases, trichobezoar is confined to stomach and rarely extends through the pylorus into jejunum, ileum or even colon $[5,6]$. Bezoar is a clinical emergency presenting with pain, intestinal obstruction, bleeding, perforation and fistulization to adjacent organs [5, 7, 8]. The complications associated with trichobezoars include gastric mucosal erosion, ulceration, intussusception, obstructive jaundice, proteinlosing enteropathy, pancreatitis and death [6, 9-11]. In cases with visceral perforation and peritonitis, the mortality approaches $100 \%$ in the absence of a surgical intervention [10].

Gastrointestinal (GI) bezoars are aggregates of inedible or undigested material found in the GI tract [12] and can be classified as phytobezoar, trichobezoar, lactobezoar, pharmacobezoar and miscellaneous (fungus, sand, paper, etc.) [13-15]. The most frequent type of bezoar in children and teenage girls is trichobezoars, while phytobezoar are more often found in adults. [16] A number of predisposing factors may contribute to the risk of bezoar formation, primarily previous gastric surgery as reported in as many as $20 \%$ of patients. Other risk factors include diabetes mellitus, trichotillomania, trichophagia, anxiety disorders, psychiatric disorders, poor mastication, excessive intake of fiber and cystic fibrosis $[5,17]$. 
Trichotillomania is characterized by an irresistible desire to pull out the hair from the scalp (non-scaring alopecia), eyelashes, eyebrows and other parts of the body. The process results in an instant release of tension, a sense of relief and security. The prevalence rate of trichotillomania as reported by different studies varies from $0.06 \%$ to as high as $3.4 \%$ and is almost exclusively seen in females [18-20]. The trichobezoar sometimes extend through the pylorus into the small bowel where the tail may break off and causes intestinal obstruction, called Rapunzel syndrome [21, 22] in few cases, which has been almost exclusively reported in adolescent females and is associated with trichotillomania and trichophagia [23].

At an early stage, most trichobezoars are asymptomatic or may present with subtle symptoms such as nausea or early satiety [24]. As trichobezoar enlarges, it may present with the signs and symptoms of acute abdomen and gastric tract obstruction which include abdominal pain, nausea, bilious vomiting, hematemesis, anorexia, early satiety, weakness, weight loss and abdominal mass, depending on the degree of obstruction [8, 10, 12, 15]. These symptoms are mostly accompanied with the psychiatric illness and behavioral disorders.

The diagnosis of trichobezoar is based on image-based evidence. Ultrasonography and computed tomography (CT) scan both are effective in detecting an epigastric mass, although CT scan is more accurate with the ability to identify the presence of additional gastrointestinal bezoars. The definite diagnosis is established by endoscopy or postextraction examination of the mass or histology $[1,7,15]$. Additionally, the psychiatric factors such as, mental retardation should be considered for the emotional and behavioral disorders based suspicion for gastric bezoar, secondary to ingestion of foreign bodies [25]. For a comprehensive diagnosis, the history of psychiatric comorbidity, trichotillomania (TTM) and trichophagia, are supportive evidence especially among girls.

The intervention practices comprise of endoscopy, laparoscopy or laparotomy $[6,10,11,24,26]$. A further rare complication of Rapunzel syndrome leads to gastric perforation [24, 25]. These conditions make endoscopic removal of trichobezoar as difficult and mandates for its management through laparotomy. Trichobezoar demand aggressive management in order to prevent a possibly lifethreatening condition with important medical and surgical morbidity.

This study aims to report our experience at a single institution with the rare and complex trichobezoar condition and the successful extraction by laparotomy and gastrotomy.

\section{Methods}

Between 2016 and 2019, two patients have been treated for trichobezoar at Lord Mahavir, Civil Hospital, Ludhiana. Their medical charts were reviewed with respect to symptoms, diagnostic procedures and treatment.

\section{Case Presentation}

\subsection{Chief Complaints}

Case 1: A 14-year-old girl visited the surgery OPD with epigastric discomfort and colicky pain associated with nausea and vomiting for two months.

Case 2: A 19-year-old girl had persistent vomiting and constipation and early satiety for one month.

\subsection{History of Present Illness}

Case 1: The patient had been on pain killers off and on for past two years.

Case 2: The patient had a history of trichophagia.

\subsection{History of Past Illness}

Case 1: She lived with her parents and had no evidence of psychiatric illness, drug history and no prior surgical history.

Case 2: The patient had the history of day-care admission for pain and vomiting two months ago.

\subsection{Personal and Family History}

No present and family history was revealed for both of the cases.

\subsection{Physical Examination}

Case 1: A clinical examination revealed a fully conscious, mildly dehydrated, pale child with no evidence of icterus. The physical examination revealed a distended gastric area with normal bowel sounds and a soft abdominal wall. A solid mass was palpable in the epigastric region, extending well below the umbilicus. However, there was no tenderness or rebound tenderness. It was concluded that the patient used to eat hair (trichophagia) during her sleep. Her parents denied that the girl had any habits of hair pulling or chewing. The patient had stable vital signs with height and weight both in the $25^{\text {th }}$ percentile.

Case 2: The clinical examination of the lean and thin built girl showed a large non-tender, firm, oval and non-pulsatile mass in the left hypochondrium extending up to the umbilicus, was mobile side-to-side with a smooth surface.

\subsection{Laboratory Examinations}

Case 1: The routine haemogram showed anemia (hemoglobin of $7.8 \mathrm{mg} / \mathrm{dl}$ ) rest all investigations were within normal limit (WNL; WBC count of $9000 / \mu 1$, platelets of $35,000 / \mathrm{ml}$ ). Other laboratory findings, including electrolytes, liver function tests, and renal function tests, were within normal limits.

Case 2: The routine haemogram showed hemoglobin of $9.2 \mathrm{mg} / \mathrm{dl}$, rest all parameters were WNL.

The detailed patient characteristics for both the cases are presented in Table 1.

\subsection{Imaging Examinations}

Case 1: An ultrasound scan performed a year earlier raised 
suspicion of a dermoid cyst. On further evaluation a CT scan reported a large well-defined intraluminal mesh like mass, the filling defect and outline by oral contrast was suggestive of a gastric Bezoar (Figure 1a, b). There was no evidence of obstruction to the contrast flow into the duodenum.
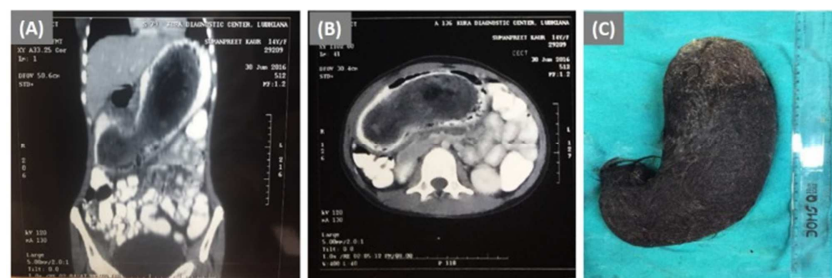

Figure 1. Case 1 (A, B) Abdominal tomography with a mesh like mass in the gastric lumen, suggestive of gastric bezoar; (C) extracted trichobezoar.

Case 2: The CT scan showed a large well-defined oval mass occupying the entire gastric cavity with oral contrast trapped within the interstices (Figure 2a). A free flow of contrast was present in duodenum and rest of bowel loops. Endoscopy could not be performed due to the financial constraints.
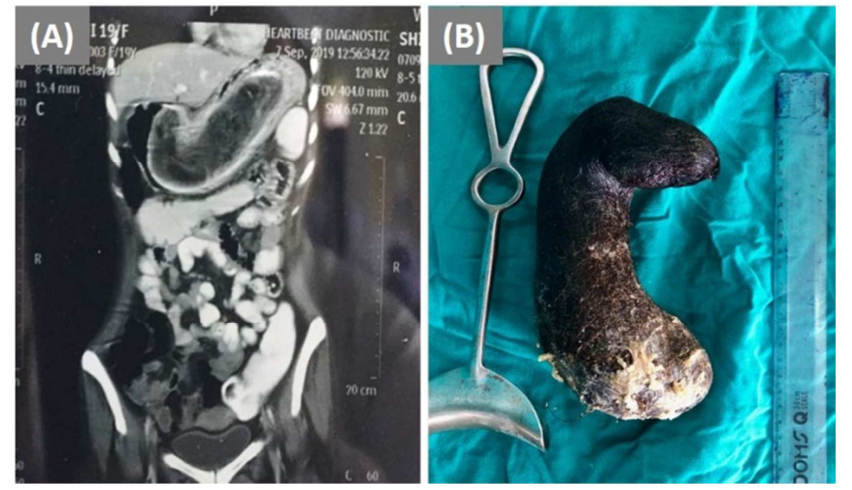

Figure 2. Case 2 (A) Abdominal tomography showing the bezoar occupying the gastric lumen; (B) extracted trichobezoar.

\subsection{Further Diagnostic Work-up}

Case 1: The girl did not show any signs of anxiety, depression, or mental retardation during admission. Bilateral hairless regions were noticed in the parietal areas on scalp.

\subsection{Final Diagnosis}

The final diagnosis was based on the abdominal imaging using $\mathrm{CT}$ scan in both the cases.

\section{Surgical Intervention}

\subsection{Case 1}

Pre-operative conservative management was initiated by stopping oral feeding and starting intravenous fluids and transfusion of one unit of blood. The surgical intervention consisted of anterior gastrotomy. After entering the abdomen and retracting the abdominal wall to provide adequate exposure to stomach, a gastric incision on ventral surface of stomach in an area that appears hypo-vascular along the greater curvature away from the pylorus was given for removal of bezoar. An adequate size incision allowed the bezoar to be gently pushed towards the fundus and evacuated obliquely to avoid trauma to stomach. The extracted bezoar weighed $1.935 \mathrm{~kg}$, measuring $25 \times 12 \times 8 \mathrm{~cm}$ (Figure 1c).

\subsection{Case 2}

For surgical intervention, midline exploratory laparotomy was performed. The gastrotomy with an incision along greater curvature revealed a huge mass of hair. The $1.5 \mathrm{~kg}$ bezoar measuring $22 \times 10 \times 7 \mathrm{~cm}$ was extracted (Figure $2 \mathrm{~b}$ ). Multiple gastric ulcerations were also noted. The gastrotomy was repaired and nasogastric tube was placed for 5 days.

Removal of the trichobezoar from the stomach must be done carefully and a key aspect of this is to peel the gastric wall away from the bezoar - much like peeling a banana. Patience and gentle manipulation at this stage will ensure the size of the gastrotomy and hair spillage into the peritoneum is minimized. Specimen extraction can be done by morselization through the umbilical port site, via midline laparotomy or by pfannensteil incision [27].

\section{Outcome and Follow-up}

Detailed outcomes of both the cases are reported in Table 1.

Table 1. Patient characteristics and outcomes.

\begin{tabular}{lll}
\hline & Case 1 & Case 2 \\
\hline Sex & Female & Female \\
\hline Age (years) & 14 & 19 \\
Chronic abdominal pain & Yes & Yes \\
Vomiting & Yes & Yes \\
Weight loss & Yes & Yes \\
Alopecia & Yes & No \\
Mass palpable & Yes & Yes \\
Signs of peritonitis & No & No \\
Psychiatric comorbidity & Trichophagia & Trichophagia \\
Laboratory results & (during sleep) & \\
Hb (mg/dl) & & \\
Diagnosis made before surgery & 7.8 & 9.2 \\
with CT scan & Yes & Yes \\
Intraoperative findings & & \\
Location & Stomach & Stomach \\
Gastric ulceration & Absent & Present \\
Trichobezoar dimension (cm) & $25 \times 12 \times 8$ & $22 \times 10 \times 7$ \\
Trichobezoar weight (kg) & 1.935 & 1.5 \\
Rapunzel syndrome & Absent & Absent \\
Postoperative follow up & & Hypertrophic scar at \\
Postoperative complications & No & the midline incision \\
Recurrence & No & No \\
Psychiatric follow up & Yes till 2018 & Yes \\
\hline
\end{tabular}

\subsection{Case 1}

The patient was stable postoperatively and was discharged without any complications on the $7^{\text {th }}$ day. The patient was advised for child psychiatric evaluation on discharge and she remained on regular follow-up for 2 years without any recurrence. 


\subsection{Case 2}

The post-operative period was uneventful. The patient was discharged on $7^{\text {th }}$ day and she remained on the regular follow-up till 25 June, 2020, was doing well without any recurrence of the symptoms.

\section{Discussion}

Trichobezoar formation are reported as a rare clinical condition with primary manifestation of a psychiatric illness [28]. Among psychiatric disorders, psychiatric illness with trichotillomania and trichophagia are the major risk factors for the development of trichobezoars [10, 17, 24, 26]. Approximately $10 \%$ of patients with trichotillomania actually demonstrate trichophagia as part of their ritualistic behavior and only $1 \%$ of patients with trichophagia develop a trichobezoar [23]. The psychiatric ailments, such as mental disorders, abuse, pica, obsessive-compulsive disorder, depression and anorexia nervosa have also been reported to be associated with trichobezoar [10, 19]. All the characteristic symptoms including nausea, vomiting, epigastric colicky pain along with trichotillomania and trichophagia were reported in both the cases in this study. However, in one patient the trichophagia during sleep was a novel observation, although the patient did not show any sign of anxiety, depression, or mental retardation during admission.

Diagnosis of trichobezoars usually depend on the case history, examination and diagnostic imaging with ultrasonography, endoscopy and the computerized tomography. An early diagnosis is highly recommended as the larger trichobezoars can lead to obstructive pathology and/or gastric or intestinal perforation. The complications like Rapunzel syndrome could even be fatal $[6,11]$. The preoperative differential diagnosis for trichobezoar include appendicitis, gastroenteritis, and intussusception [22]. In a case study for presentation of a small-bowel obstruction secondary to trichobezoar in a Meckel's diverticulum, the (Hetero) anamnesis and physical examination were reported as crucial in the detection and in reducing overdiagnosis and overtreatment. Further, physical examination is indicated to provide crucial evidence in preoperative diagnosis of trichobezoar in the presence of patchy alopecia [22]. Although the best and confirmatory tool for the diagnosis is endoscopy [11], in the reported cases, endoscopy could not be performed due to financial constraints and unavailability. The CT scan of abdomen with oral contrast provided a fair estimate of type and the size of the bezoars. History of trichotillomania and trichophagia proved very important to corroborate the tomographic findings.

Trichobezoar can be removed and treated using endoscopy, laparoscopy or Laparotomy. Endoscopy with several reports of unsuccessful attempts is less preferred in evacuating the gastric bezoars [25].

The surgical removal of the bezoar is generally accomplished via laparotomy and gastrotomy. Rapunzel syndrome most often does not necessitate the multiple enterotomies as the bezoar can be generally removed through the gastrotomy. However, there remain a risk of possible fragmentation of the bezoar while pulling back, which may cause small bowel obstruction [25]. Thus, for the treatment of trichobezoar, laparotomy is the most preferred option and is reported with $100 \%$ success rate as compared to $75 \%$ for laparoscopy and 5\% for endoscopy $[6,10,11]$ The nonsurgical management of trichobezoars are associated with the high mortality rates $[5,6,10]$. The trichobezoar size varies from a small $(2 \times 2 \mathrm{~cm}$ in diameter $)$ [5] to giant size $(30 \times 15$ $\times 10 \mathrm{~cm} \mathrm{[24]} \mathrm{to} 25 \times 18 \times 7.5 \mathrm{~cm}$ [29]). The size of two trichobezoar $(25 \times 12 \times 8 \mathrm{~cm}$ and $22 \times 10 \times 7 \mathrm{~cm})$ in the presented cases was quite large and could have led to complications if left untreated for some more time. Both the large bezoars in the present study were successfully evacuated using the exploratory laparotomy and gastrotomy.

The post-operative psychiatric consultation is crucial to prevent recurrence and to treat comorbid conditions that usually accompany this disorder. Psychiatric referral after surgical treatment of a trichobezoar are suggested as an essential part of successful treatment and prevention of recurrence $[10,11,29]$. The patients in the study were referred to the psychiatric department and showed improvement in the trichotillomania and trichophagia upon counselling. The uneventful follow-up without any gastrointestinal symptoms corroborated the importance of psychiatric evaluation and counselling in the prevention of recurrence of trichobezoars.

\section{Conclusion}

Trichobezoar should be considered as a differential diagnosis in a young female patient with a mobile epigastric mass. Radiological diagnosis is recommended with the use of endoscopy and CT scan. The larger bezoars almost always require surgical evacuation. It is emphasized that a multidisciplinary approach including psychiatric follow-up is essential to prevent the recurrence as a majority of the patients have an underlying psychiatric or social disorder.

\section{Acknowledgements}

Authors thanks Dr. Amit Kishore and Charu Rawat from AccuScript Consultancy Pvt. Ltd., Ludhiana, India for development and editing of the manuscript.

\section{References}

[1] Carr JR, Sholevar EH, Baron DA. Trichotillomania and trichobezoar: a clinical practice insight with report of illustrative case. J Am Osteopath Assoc 2006; 106 (11): 647 652 [PMID: 17192451].

[2] Diefenbach GJ, Reitman D, Williamson DA. Trichotillomania: a challenge to research and practice. Clin Psychol Rev 2000; 20 (3): 289-309 [PMID: 10779896 DOI: 10.1016/s02727358(98)00083-x]. 
[3] Kuntoji V, Kudligi C, Bhagwat PV, Asati DP, Bansal A. The tricky "trichs" in dermatology! Indian J Dermatol Venereol Leprol 2018; 84 (1): 109-113 [PMID: 29243672 DOI: 10.4103/ijdvl.IJDVL_1019_16].

[4] Shorter E. A historical dictionary of psychiatry. New York: Oxford University Press; 2005.

[5] Gokbulut V, Kaplan M, Kacar S, Akdogan Kayhan M, Coskun O, Kayacetin E. Bezoar in upper gastrointestinal endoscopy: A single center experience. Turk J Gastroenterol 2020; 31 (2): 85-90 [PMID: 32141815 PMCID: 7062142 DOI: $10.5152 /$ tjg.2020.18890].

[6] Mirza MB, Talat N, Saleem M. Gastrointestinal trichobezoar: An experience with 17 cases. J Pediatr Surg 2020 [PMID: 32467033 DOI: 10.1016/j.jpedsurg.2020.04.020].

[7] Coulter R, Antony MT, Bhuta P, Memon MA. Large gastric trichobezoar in a normal healthy woman: case report and review of pertinent literature. South Med J 2005; 98 (10): 1042-1044 [PMID: 16295823 DOI: 10.1097/01.smj.0000182175.55032.4a].

[8] Pérez E, Ramón Sántana J, García G, Mesa J, Ramón Hernández J, Betancort N, Núñez V. Perforación gástrica en adulto por tricobezoar (síndrome de Rapunzel). Cirugía $\begin{array}{lllll}\text { Española 2005; } 78 \text { (4): 268-270 [DOI: } & \end{array}$ https://doi.org/10.1016/S0009-739X(05)70931-3].

[9] Ventura DE, Herbella FA, Schettini ST, Delmonte C. Rapunzel syndrome with a fatal outcome in a neglected child. $J$ Pediatr Surg 2005; 40 (10): 1665-1667 [PMID: 16227005 DOI: 10.1016/j.jpedsurg.2005.06.038].

[10] Kwok AMF. Trichobezoar as a cause of pediatric acute small bowel obstruction. Clin Case Rep 2020; 8 (1): 166-170 [PMID: 31998509 PMCID: 6982476 DOI: 10.1002/ccr3.2576].

[11] Al-Osail EM, Zakary NY, Abdelhadi Y. Best management modality of trichobezoar: A case report. Int J Surg Case Rep 2018; 53: 458-460 [PMID: 30567068 PMCID: 6275210 DOI: 10.1016/j.ijscr.2018.11.030].

[12] Eng K, Kay M. Gastrointestinal bezoars: history and current treatment paradigms. Gastroenterol Hepatol (N Y) 2012; 8 (11): 776-778 [PMID: 24672418 PMCID: PMC3966178].

[13] Iwamuro M, Okada H, Matsueda K, Inaba T, Kusumoto C, Imagawa A, Yamamoto K. Review of the diagnosis and management of gastrointestinal bezoars. World J Gastrointest Endosc 2015; 7 (4): 336-345 [PMID: 25901212 PMCID: PMC4400622 DOI: 10.4253/wjge.v7.i4.336].

[14] Paschos KA, Chatzigeorgiadis A. Pathophysiological and clinical aspects of the diagnosis and treatment of bezoars. Ann Gastroenterol 2019; 32 (3): 224-232 [PMID: 31040619 PMCID: PMC6479654 DOI: 10.20524/aog.2019.0370].

[15] Sehgal VN, Srivastava G. Trichotillomania +/- trichobezoar: revisited. J Eur Acad Dermatol Venereol 2006; 20 (8): 911915 [PMID: 16922936 DOI: 10.1111/j.14683083.2006.01590.x].

[16] Frey AS, McKee M, King RA, Martin A. Hair apparent: Rapunzel syndrome. Am J Psychiatry 2005; 162 (2): 242-248 [PMID: 15677585 DOI: 10.1176/appi.ajp.162.2.242].
[17] Kement M, Ozlem N, Colak E, Kesmer S, Gezen C, Vural S. Synergistic effect of multiple predisposing risk factors on the development of bezoars. World J Gastroenterol 2012; 18 (9): 960-964 [PMID: 22408356 PMCID: PMC3297056 DOI: 10.3748/wjg.v18.i9.960].

[18] American Psychiatric Association. Diagnostic and Statistical Manual of Mental Disorders, Fourth Edition, Text Revision (DSM-IV-TR). 2000, Washington.

[19] França K, Kumar A, Castillo D, Jafferany M, Hyczy da Costa Neto M, Damevska K, Wollina U, Lotti T. Trichotillomania (hair pulling disorder): Clinical characteristics, psychosocial aspects, treatment approaches, and ethical considerations. Dermatol Ther 2019; 32 (4): e12622 [PMID: 30152568 DOI: 10.1111/dth.12622].

[20] Duke DC, Keeley ML, Geffken GR, Storch EA. Trichotillomania: A current review. Clin Psychol Rev 2010; 30 (2): 181-193 [PMID: 19926375 DOI: 10.1016/j.cpr.2009.10.008].

[21] Naik S, Gupta V, Naik S, Rangole A, Chaudhary AK, Jain P, Sharma AK. Rapunzel syndrome reviewed and redefined. Dig Surg 2007; 24 (3): 157-161 [PMID: 17476105 DOI: $10.1159 / 000102098]$.

[22] Otten MJ, Charehbili A, Duinhouwer LE. Small-Bowel Obstruction Secondary to a Trichobezoar in a Meckel's Diverticulum in a Patient with Rapunzel Syndrome. $J$ Gastrointest Surg 2020; 24 (5): 1220-1221 [PMID: 31745891 DOI: $10.1007 / \mathrm{s} 11605-019-04448-\mathrm{x}]$.

[23] Fallon SC, Slater BJ, Larimer EL, Brandt ML, Lopez ME. The surgical management of Rapunzel syndrome: a case series and literature review. J Pediatr Surg 2013; 48 (4): 830-834 [PMID: 23583142 DOI: 10.1016/j.jpedsurg.2012.07.046].

[24] Antunes H, Barroso C, Faria C, Correia-Pinto J. Images in paediatrics: Rapunzel syndrome: the pathway for a prompt diagnosis. Arch Dis Child 2020; 105 (3): 298 [PMID: 30509953 DOI: 10.1136/archdischild-2018-315910].

[25] Castle SL, Zmora O, Papillon S, Levin D, Stein JE. Management of Complicated Gastric Bezoars in Children and Adolescents. Isr Med Assoc J 2015; 17 (9): 541-544 [PMID: 26625542].

[26] Placone N, Mann S. A Trichobezoar of Gastric Proportions. Clin Gastroenterol Hepatol 2020; 18 (2): e18 [PMID: 30342915 DOI: 10.1016/j.cgh.2018.10.023].

[27] Zmudzinski M, Hayashi A. Laparoscopic removal of massive pediatric gastric trichobezoars: A brief report. Am J Surg 2020; 219 (5): 810-812 [PMID: 32063342 DOI: 10.1016/j.amjsurg.2020.01.048].

[28] Gupta A, Mittal D, Srinivas M. Gastric Trichobezoars in Children: Surgical Overview. Int J Trichology 2017; 9 (2): 5053 [PMID: 28839386 PMCID: PMC5551305 DOI: 10.4103/ijt.ijt_38_17].

[29] Wang CK, Chen JC, Chang FY. A giant trichobezoar in a young girl: A case report. Pediatr Neonatol 2020; 61 (2): 241242 [PMID: 31629666 DOI: 10.1016/j.pedneo.2019.09.011]. 